reduce overall costs and may identify patients earlier, protocol based isoniazid prophylaxis is effective in preventing active tuberculosis.

Conclusion While Isoniazid prophylaxis was effective in prevention of subsequent tuberculosis, screening prior to transplantation should have identified both patients who developed TB.

\section{P111 OLDER PATIENTS WITH TUBERCULOSIS HAVE LESS TYPICAL CHANGES ON CHEST RADIOGRAPHS}

${ }^{1} \mathrm{~A}$ Abbara, ${ }^{1} \mathrm{Z}$ Mahomed, ${ }^{2} \mathrm{SM}$ Collin, ${ }^{3} \mathrm{OM}$ Kon, ${ }^{1} \mathrm{~V}$ Bushell, ${ }^{4} \mathrm{~K}$ Buell, ${ }^{4} \mathrm{JAL}$ Sullivan, ${ }^{5} \mathrm{~T}$ Hansel, ${ }^{1} \mathrm{~T}$ Corrah, ${ }^{1} \mathrm{RN}$ Davidson. 'London North West Healthcare NHS Trust, London, UK; ${ }^{2}$ University of Bristol, Bristol, UK; ${ }^{3}$ Imperial Healthcare NHS Trust, London, UK; ${ }^{4}$ Imperial College, London, UK; ${ }^{5} \mathrm{NHLI}$, Imperial College, London, UK

\subsection{6/thoraxjnl-2016-209333.254}

Introduction and objectives It has been suggested that TB has a different phenotype in older patients with age-related changes to the cell-mediated immune response and co-existent organ dysfunction. Older patients with tuberculosis (TB) may have different radiographic features than younger patients; this may lead to less immediate suspicion of $\mathrm{TB}$ resulting in delays to diagnosis and starting treatment. We wanted to identify if there are differences in the most common radiological differences in older and younger patients with pulmonary TB (PTB).

Methods Patients with PTB $>65$ were noted from the London TB register between 2002 and 2015. A random selection of

\begin{tabular}{|c|c|c|c|c|}
\hline $\begin{array}{l}\text { Total number of patients } \\
\text { with CXR reports }\end{array}$ & \multicolumn{2}{|l|}{525} & \multicolumn{2}{|l|}{184} \\
\hline Median age (IQR) & \multicolumn{2}{|l|}{$30(26-34)$} & \multicolumn{2}{|l|}{$73(69-78)$} \\
\hline Gender & \multicolumn{2}{|c|}{196 female, 329 male } & \multicolumn{2}{|c|}{79 female, 105 male } \\
\hline UK born & \multicolumn{2}{|l|}{$45(8.6 \%)$} & \multicolumn{2}{|c|}{$13(7.1 \%)$} \\
\hline Pulmonary TB patients & \multicolumn{2}{|l|}{$239(45.5 \%)$} & \multicolumn{2}{|l|}{$99(53.8 \%)$} \\
\hline CXR changes & Number & Percentage & Number & Percentage \\
\hline Cavitation & 36 & 15.1 & 10 & 10.1 \\
\hline Consolidation & 104 & 43.5 & 50 & 50.5 \\
\hline Nodules & 39 (7 miliary) & 16.3 & 14 (4miliary) & 14.1 \\
\hline Lymphadenopathy & 43 & 18.0 & 4 & 4.0 \\
\hline Hilar & 19 & 7.9 & 4 & 4.0 \\
\hline Mediastinal & 9 & 3.8 & - & - \\
\hline Paratracheal & 14 & 5.9 & - & - \\
\hline Effusion & 59 & 24.7 & 8 & 8.0 \\
\hline \multicolumn{5}{|l|}{ Zone of involvement } \\
\hline Upper zone involvement & 118 & 49.4 & 49 & 49.4 \\
\hline Upper and lower & 21 & 8.8 & 17 & 17.1 \\
\hline Lower & 59 & 24.7 & 31 & 31.3 \\
\hline \multicolumn{5}{|l|}{ Microbiology } \\
\hline Cultured MTB & 158 & 66.1 & 67 & 67.7 \\
\hline Smear Positive & 56 & 23.4 & 19 & 19.1 \\
\hline Fully sensitive & 146 & 61 & 61 & 61.6 \\
\hline INH resistant & 7 & 2.9 & 1 & 1.0 \\
\hline MDR & 1 & 0.4 & & \\
\hline XDR & 1 & 0.4 & & \\
\hline Diabetes & 2 & 0.8 & 28 & 28.2 \\
\hline
\end{tabular}

younger patients aged $18-40$ with PTB were also identified. All available chest $\mathrm{x}$-ray (CXR) reports were obtained from online radiology systems. CXR features were classified according to reported features with particular note of cavitation, nodules and miliary changes, consolidation, lymphadenopathy and effusions.

Results The CXR reports of 239 patients with PTB $<65$ and 99 patients with PTB $>65$ were collated. Demographic details as well as CXR changes are detailed in Table 1. Cavitation, lymphadenopathy and effusions were more common in younger patients whereas consolidation was more evident in older patients. Upper zone involvement was similar in both groups.

Conclusions Studies by other groups have suggested a higher proportion of cavitation and upper zone changes in younger patients with TB with less specific changes in older patients. This may lead to less suspicion of TB and potentially a longer infective period; this is important given that $23 \%$ and $19 \%$ of younger and older patients have smear positive PTB. In our study, the proportion with upper zone changes are similar though cavitation is more frequent in younger patients. Of note, is the much higher presence of lymphadenopathy and effusions seen in younger patients. This may potentially be related to differences in the immune function of both groups or primary infection versus reactivation. These findings re-enforce the need for clinical suspicion for PTB in both older and younger patients with both specific and non-specific radiographic changes.

\section{P112 SERUM INFLAMMATORY BIOMARKERS AS PREDICTORS OF TREATMENT OUTCOME IN PULMONARY TUBERCULOSIS}

${ }^{1} \mathrm{~A}$ Ritchie, ${ }^{1} \mathrm{~A}$ Singanayagam, ${ }^{1} \mathrm{~K}$ Manalan, ${ }^{1} \mathrm{D}$ Connell, ${ }^{2} \mathrm{~J}$ Chalmers, ${ }^{1} \mathrm{~S}$ Sridhar, ${ }^{1} \mathrm{~A}$ Lalvani, ${ }^{1} \mathrm{M}$ Wickremasinghe, ${ }^{1} \mathrm{OM}$ Kon. 'Imperial College NHS Trust, London, UK; ${ }^{2}$ Tayside Respiratory Research Group, Dundee, UK

\subsection{6/thoraxjnl-2016-209333.255}

Background The aim of this study was to evaluate C-reactive protein(CRP), globulin and white cell count as predictors of treatment outcome in pulmonary tuberculosis.

Methods An observational study of patients with active pulmonary tuberculosis was conducted at a tertiary centre. All patients had serum CRP, globulin and white cell count measured at baseline and two months following commencement of therapy. The outcome of interest was requirement for extension of therapy beyond 6 months.

Results There were 226 patients included in the study. Serum globulin $>45 \mathrm{~g} / \mathrm{L}$ was the only baseline biomarker evaluated that independently predicted requirement for therapy extension (OR 3.59 (1.79-7.57; $\mathrm{p}<0.001)$ ). An elevated globulin level that failed to normalise at 2 months was also associated with increased requirement for treatment extension $(63.9 \%$ versus $5.1 \%$; $\mathrm{p}<0.001)$ and had low negative likelihood ratio(0.07) for exclusion of requirement for therapy extension. On multivariable analysis, an elevated globulin that failed to normalise at 2 months was independently associated with requirement for therapy extension (OR 6.12 (2.23-16.80); p < 0.001).

Conclusions Serum globulin independently predicts requirement for treatment extension in pulmonary TB and outperforms CRP and white cell count as a predictive biomarker. Normalisation of globulin at two months following treatment commencement is associated with low risk of requirement for treatment extension. 